\title{
Fungal Assemblages Associated with Roots of Halophytic and Non-halophytic Plant Species Vary Differentially Along a Salinity Gradient
}

\author{
Jose G. Maciá-Vicente • Valeria Ferraro • \\ Santella Burruano $\cdot$ Luis V. Lopez-Llorca
}

Received: 12 February 2012 / Accepted: 24 April 2012

(C) Springer Science+Business Media, LLC 2012

\begin{abstract}
Structure of fungal communities is known to be influenced by host plants and environmental conditions. However, in most cases, the dynamics of these variation patterns are poorly understood. In this work, we compared richness, diversity, and composition between assemblages of endophytic and rhizospheric fungi associated to roots of two plants with different lifestyles: the halophyte Inula crithmoides and the non-halophyte I. viscosa (syn. Dittrichia viscosa L.), along a spatially short salinity gradient. Roots and rhizospheric soil from these plants were collected at three points between a salt marsh and a sand dune, and fungi were isolated and characterized by ITS rDNA sequencing. Isolates were classified in a total of 90 operational taxonomic units (OTUs), belonging to 17 fungal orders within Ascomycota and Basidiomycota. Species composition of endophytic and soil communities significantly differed across
\end{abstract}

Electronic supplementary material The online version of this article (doi:10.1007/s00248-012-0066-2) contains supplementary material, which is available to authorized users.

J. G. Maciá-Vicente $(\bowtie) \cdot$ L. V. Lopez-Llorca

Multidisciplinary Institute for Environmental Studies (MIES)

"Ramón Margalef," Department of Marine Sciences and Applied Biology, University of Alicante,

Apto. 99,

03080 Alicante, Spain

e-mail: jgmv@ua.es

V. Ferraro $\cdot$ S. Burruano

Department DEMETRA, Università degli Studi di Palermo,

Viale delle Scienze 2,

90128 Palermo, Italy

Present Address:

J. G. Maciá-Vicente

U.S. Geological Survey,

6505 65th St NE,

Seattle, WA 98115 , USA samples. Endophyte communities of I. crithmoides and I. viscosa were only similar in the intermediate zone between the salt marsh and the dune, and while the latter displayed a single, generalist association of endophytes, I. crithmoides harbored different assemblages along the gradient, adapted to the specific soil conditions. In the lower salt marsh, root assemblages were strongly dominated by a single dark septate sterile fungus, also prevalent in other neighboring salt marshes. Interestingly, although its occurrence was positively correlated to soil salinity, in vitro assays revealed a strong inhibition of its growth by salts. Our results suggest that host lifestyle and soil characteristics have a strong effect on endophytic fungi and that environmental stress may entail tight plant-fungus relationships for adaptation to unfavorable conditions.

\section{Introduction}

Fungal endophytes can be found colonizing the tissues of all plants, irrespective of their taxonomical affiliation or environmental preferences. Several works point out that mutualistic interactions between plants and their associated fungal consortia are of paramount relevance for the distribution of plant communities worldwide, through increasing host fitness and assisting in adaptation to environmental and biological stresses [1-4]. Endophytic colonization of aboveground plant tissues may lead to beneficial effects to the host (e.g., [5]), for instance, in some grasses where Clavicipitaceous endophytes (classified as class 1 endophytes in [6]) are responsible for herbivory resistance [7]. However, it is generally assumed that most plant-fungus mutualistic interactions take place in roots, due to a more systemic colonization [6, 8]. According to [6], such mutualisms involve endophytes within classes 2 and 4, in combination with a plethora of other symbionts such as mycorrhizae 
and endophytic bacteria. There are evidences that mycorrhizal populations become reduced or absent in habitats subjected to certain environmental stresses (e.g., $[9,10])$, thus leaving those niches to be exploited by other fungal symbionts, such as the so-termed dark-septate endophytes (DSE; [11]). The mechanistic processes responsible for the mutual benefits between plant and endophytes are still cryptic [12], partly due to the broad taxonomical and functional diversity of these interactions, but also to the unspecificity of the mutualism. As an example, a single plant may harbor a good diversity of associated microbes [13] playing different roles within the plant tissues, covering the range between mutualism, through commensalism, to eventual pathogenicity. In the meantime, these plant inhabitants may interact with each other in very different manners. The final plant performance will be undoubtedly influenced by a synergy of this complex of interactions. Hitherto, little is known about the function of fungal root endophytic assemblages as a whole in plant performance, but several studies have highlighted the evident effects provided by individual fungal partners. These can lead to a plant to cope with conditions which its own adaptations would not allow [2]. Whether fungal symbionts also participate in enhancing tolerance to a specific stress in plants with existing adaptive mechanisms is still not known, albeit previous observations suggest this possibility [14].

Environmental gradients represent unique conditions to study mutualistic interactions leading to environmental settlement. Such conditions can be found in dune slacks from SE Spain. These are depressions between sand dunes with high soil salt content due to vicinity to sea water, which are partially or completely flooded periodically during the year, and therefore present specific halophytic plant assemblages. They represent "halophylic islands" displaying abrupt edaphic changes at a relative small spatial scale and consequently are a suitable gradient to assess the effects of soil conditions and vegetation on fungal assemblages. In the present work, we studied fungal communities associated to roots of two phylogenetically related plant species which dwell in dune slacks and which express different lifestyles. Inula crithmoides L. is a halophyte commonly found in salt marshes. Inula viscosa L. (Ait.) (syn. Dittrichia viscosa L.) is a ubiquitous and nitrophilous species, which is, to some extent, tolerant to salt but cannot be considered a halophyte [15]. A previous characterization of fungal root endophytic communities in sand dunes and salt marshes in SE Spain showed a tendency of fungal assemblages to change according to either of the two soil conditions at a larger scale [16]. The aim of this study was to compare fungal root endophytic communities between the halophytic and non-halophytic Inula species along a gradient to assess how spatial patterns of distribution are influenced by the host or soil conditions. Associated rhizosphere soil fungi were also studied to analyze the variation of non-endophyte communities under the same conditions.

\section{Methods}

\section{Sampling Sites}

The site of the present study is located in the dune system "El Carabassí," ca. $10 \mathrm{~km}$ south of Alicante city (Spain). It is a well-developed dune system comprising embryonic, mobile, immobile, and fossil dunes with interspersed slacks. Four of these, distributed parallel to sea line along ca. $270 \mathrm{~m}$, were selected for samplings and were named as M1 (4235144.95 N; 717609.11 E), M2 (4235146.26 N; 717617.09 E), M3 (4235335.79 N; 717542.18 E), and M4 $(4235380.22 \mathrm{~N} ; 717524.88 \mathrm{E})$. Each site was divided into three zones comprising the lower salt marsh (A), an intermediate zone (B), and the top of the closest sand dune (C) towards the sea. Vegetation in zone A was characterized by halophytic plant communities adapted to high water content, conforming Holoschoenetum romani + Br.-B1., Roussine \& Nègre 1952 associations dominated by Juncus acutus (L.) Torr. ex Retz. and Scirpus holoschoenus L., and with a high occurrence of $I$. crithmoides (especially in sites M1 and M4). Zone C included sand vegetation dominated by Sporobolus pungens (Schreber) Kunth and Ammophila arenaria subsp. australis (L.) Link, with sporadic occurrence of $I$. crithmoides. For all sites, I. viscosa was present in zones B and $\mathrm{C}$, but was absent in zone $\mathrm{A}$.

\section{Characterization of Soils}

Three soil samples were taken from each zone A-C at site M1 and zone A at sites M2-4. Physicochemical parameters (conductivity, $\mathrm{pH}$, carbonates, active limestone, organic matter, water content, texture, granulometry, and phosphorus content) were determined by the Common Research Facilities from the University of Alicante. ANOVA tests were performed to analyze differences among soil sites and parameters, and a principal component analysis (PCA) was done with the standardized variables to summarize the patterns of variation among sampling points.

Diversity of Root Endophytes and Soil Fungi

\section{First Sampling}

A first sampling to analyze the endophytic and rhizospheric soil mycobiota associated with I. crithmoides and I. viscosa was carried out in February 2009 at site M1. Three individuals of $I$. crithmoides (Ic) and I. viscosa (Iv) were collected from zones B (IcB, IvB) and C (IcC, IvC). Since I. viscosa 
was absent in zone A, only three I. crithmoides individuals were collected in this zone (IcA). In all cases, apparently healthy, medium-sized plants were selected. Whole plants and associated rhizospheric soil were taken and kept in plastic bags at $4{ }^{\circ} \mathrm{C}$ until processing, never later than $48 \mathrm{~h}$ after sampling.

\section{Isolation of Endophytic and Soil Fungi}

For isolation of fungal endophytes from roots, root samples were first washed thoroughly under running tap water and then surface-sterilized in a $3 \%$ sodium hypochlorite solution with $0.02 \%$ Tween 20 (Sigma, St Louis, MD, USA) for $3 \mathrm{~min}$, followed by three rinses in sterilized distilled water and dry-blotting onto sterilized filter paper. Sterilized roots were cut into ca. $0.3-\mathrm{cm}$ pieces, and 300 root pieces per plant were plated on Petri dishes containing $0.5 \%$ malt extract agar (MEA, Scharlau, Barcelona, Spain) supplemented with $0.1 \%(\mathrm{v} / \mathrm{v})$ Triton X-100 (Sigma) and 0.5-g L ${ }^{-1}$ chloramphenicol (Sigma). Prior to plating, a subset of root pieces were imprinted onto fresh medium to check the surface-sterilization procedure. No mycelial growth developed from these root imprints. The remaining root material was frozen at $-76{ }^{\circ} \mathrm{C}$ until further processing. Three to six weeks after plating, development of fungal colonies from root pieces was assessed, and these were individually subcultured on potato-dextrose agar plates (PDA, Oxoid, Hampshire, UK) supplemented with 0.5 -g L $\mathrm{L}^{-1}$ chloramphenicol.

For isolation of fungi from rhizospheric soil, a subsample of $1 \mathrm{~g}$ from each soil sample was suspended in $9 \mathrm{~mL}$ of a sterilized $0.05 \%$ agar solution and serially diluted. Each suspension was used to plate 10 Petri dishes containing the growth medium previously described. Another subsample of $1 \mathrm{~g}$ from each soil was left at room temperature for 1520 days, and then, its dry weight was measured. One to two weeks after plating, colony forming units (CFUs) were recorded for each unique fungal colony morphology, and CFUs per $g$ of dry soil was calculated. Representatives for unique colony morphologies were subcultured in pure cultures as previously described.

\section{Characterization of Isolates}

Isolates were first grouped into morphotypes according to colony morphology and referred to fungal genera when reproductive structures were present, using appropriate taxonomic literature. For a further grouping of isolates, molecular identification of all morphotypes found was performed. Total genomic DNA was extracted from pure cultures of representatives of each morphotype using a standard CTAB-based protocol [17]. PCR was used to amplify the internal transcribed spacer (ITS1 and 2) of the rDNA region and the $5.8 \mathrm{~S}$ gene using primers ITS1F and ITS4 [18, 19]. Sequencing was performed by Macrogen Inc. Sequencing Service (Seoul, Korea) using ITS $1 F / 4$ primers.

Sequences were edited and assembled using EMBOss v6.1.0 [20] to get a total of 240 contigs representing all morphotypes. Contig sequences were aligned using MAFFT v6.0 [21], and then operational taxonomic units (OTUs) designated with the software MOTHUR v1.7.2 [22] using $97 \%$ sequence similarity [23], and considering gaps as single insertions. One representative sequence for each OTU was selected for further analyses. Sequences were BLAST-searched [24] using a Perl script against a local database comprising all fungal ITS sequences in GenBank as of March 2009 (fungalITSdatabase; 96,055 sequences) or against a database with only fully identified (fungalITSdatabaseID; 58,877 sequences) GenBank sequences [25]. Best matched sequences obtained in the BLAST search $(3,130$ unique sequences) were used to construct a phylogenetic tree and a taxonomic database (see the Electronic Supplementary Materials (ESM)). The database was used to assign OTU sequences to fungal taxa using the naïve Bayesian classifier [26] available in MOTHUR, with 100 bootstrap iterations. Only taxonomic assignments with bootstrap values above $60 \%$ were considered, and results were corrected manually.

The nucleotide sequences obtained in this study have been deposited in GenBank under accession numbers HQ649765-HQ650004 (Table S2 in the ESM).

\section{Analysis of Fungal Communities}

Analyses of diversity and fungal communities from isolation data were performed with use of the library vegan v1.17 for R v2.10.1 [27]. First, observed species richness and several richness estimators and diversity indices were calculated for each plant and zone, and rank-abundance curves were constructed to analyze community structures. For ordination and comparison of fungal communities, similarity matrices were calculated from data sets using the Chao similarity index [28]. Prior to this, isolation data were $\log$ $(x+1)$-transformed to minimize the weight of dominant OTUs, which could mask the influence of less frequent groups. A first matrix was obtained from a combined data set of endophytic and soil fungi presence/absence data, and species composition was compared by hierarchical cluster analysis using the Ward's method. Endophytic and soil fungi similarity matrices were separately calculated, taking into account abundance data, and were ordered through nonmetric multidimensional scaling (NMDS). Comparisons of overall fungal communities between factors root and soil, or among samples, were performed from the respective similarity matrices with permutational multivariate analysis of 
variance (PERMANOVA; [29]), using the adonis function of vegan.

\section{Microscopy of Roots}

To directly visualize fungal colonization of roots using light microscopy, ten ca. 0.5 -cm-long root pieces from each plant were stained with lactophenol cotton blue as described in [9]. Whole root pieces were mounted on microscope slides, squashed with coverslips, and viewed in a Leica DM LB $100 \mathrm{~T}$ microscope equipped with a Leica DFC480 digital camera (Leica Microsystems, Wetzlar, Germany). Low magnification $(\times 40)$ overlapping images were captured to cover all length of root pieces and then assembled into a single image.

Fungal Detection Assays

\section{Second Sampling}

In May 2009, a second sampling was performed to evaluate the presence of the dominant endophyte in zone A at M1, OTU01 (see Fig. 2), in other sites and plant organs. Three specimens of I. crithmoides were sampled in each zone A from sites M1-4 as described in "First Sampling."

\section{Culturing Methods}

Root material from each plant was processed for isolation of fungal endophytes on culture medium as in section "Isolation of Endophytic and Soil Fungi." Stem and leaf material from plants sampled only at M1 was processed similarly, but including washes of $30 \mathrm{~s}$ with $96 \%$ ethanol and $1 \mathrm{~min}$ with $70 \%$ ethanol prior and after the $\mathrm{NaOCl}$ treatment, respectively. One hundred pieces from each tissue/plant were plated in culture medium, using the imprint method to check the sterilization protocols. Remaining plant tissue material was stored at $-76{ }^{\circ} \mathrm{C}$ until further use for PCR analysis. Four weeks after plating, overall and OTU01 colonization of tissue pieces was recorded. The latter was easily recognizable because of its colony morphology and production of a dark-green pigment. Genomic DNA was isolated from selected colonies of the fungus and identified by sequencing of the ITS region.

Root colonization data were checked for normality and homogeneity of variances. Differences among groups were compared using one-way ANOVA with the Tukey Honestly Significant Difference post hoc test. Relationships between root colonization by OTU01 and soil physicochemical variables from each sampling point were investigated using Spearman's rank correlation.

\section{PCR Detection}

Primers ME3F (5'-CCTTCTGAAAAACCCAATCG-3') and ME3R (5'-GCAAAGAAGGTGGGACAGAC-3') were designed to specifically amplify a 230 -bp region of the OTU01 ITS rDNA. Specificity of primers was checked by PCR using DNA from several target and non-target fungal isolates (Fig. S2 in the ESM).

Total genomic DNA was obtained from leaves, stems, roots, and rhizospheric soil from plants collected at M1 using existing protocols $[30,31]$. Three independent DNA extractions were performed per tissue or soil sample and amplified separately by PCR. Amplifications were carried out in a final volume of $25 \mu \mathrm{L}$ containing $1 \times$ Flexi buffer, 2$\mathrm{mM} \mathrm{MgCl} 2,0.2-\mathrm{mM}$ dNTPs, $0.5 \mu \mathrm{M}$ of each ME3F and ME3R primers, $40 \mathrm{ng}$ of DNA template, and 1 unit of GoTaq DNA polymerase (Promega Corp., Madison, WI, USA). Temperature cycles consisted of a denaturation step of $95{ }^{\circ} \mathrm{C}$ for $8 \mathrm{~min}, 40$ cycles of $95^{\circ} \mathrm{C}$ for $30 \mathrm{~s}, 60^{\circ} \mathrm{C}$ for $20 \mathrm{~s}$, and $72{ }^{\circ} \mathrm{C}$ for $30 \mathrm{~s}$, and a final extension step of $72{ }^{\circ} \mathrm{C}$ for 5 min. Positive amplification controls for each sample were performed with primers ITS1F/4. Positive amplification controls for each PCR mix were performed using $1 \mathrm{ng}$ of genomic DNA from OTU01 as template. In negative controls, templates were replaced by water to rule out contamination. Positive amplification reactions were purified and sequenced with primers $\mathrm{ME} 3 \mathrm{~F} / \mathrm{R}$ to verify that they belonged to OTU01.

\section{Effect of Salt on Fungal Growth}

Sodium chloride effect on hyphal growth of seven dominant endophytes and soil fungi (OTU01, OTU03, OTU07, OTU16, OTU29, OTU44, and OTU80) was tested on agar plates. Sucrose was also used as an alternative osmolyte in these tests. Fungi were plated per triplicate on water-agar plates containing $0,10,100,200,300$, or $500 \mathrm{mM}$ of either sodium chloride or sucrose, and colony diameters were recorded periodically within 1-10 days after plating. These data were used to calculate the growth rate for each fungus/ treatment.

\section{Results}

Physicochemical Soil Parameters

The relationships among the physicochemical soil variables of the sites sampled (Table S1 in the ESM) were investigated by means of a PCA (Fig. 1). Soils M1A and M4A had the highest conductivity, water content, and coarsest particle size. Soils $\mathrm{A}-\mathrm{C}$ from site $\mathrm{M} 1$ displayed the highest $\mathrm{pH}$ and carbonates content, and the lowest phosphorus content, 


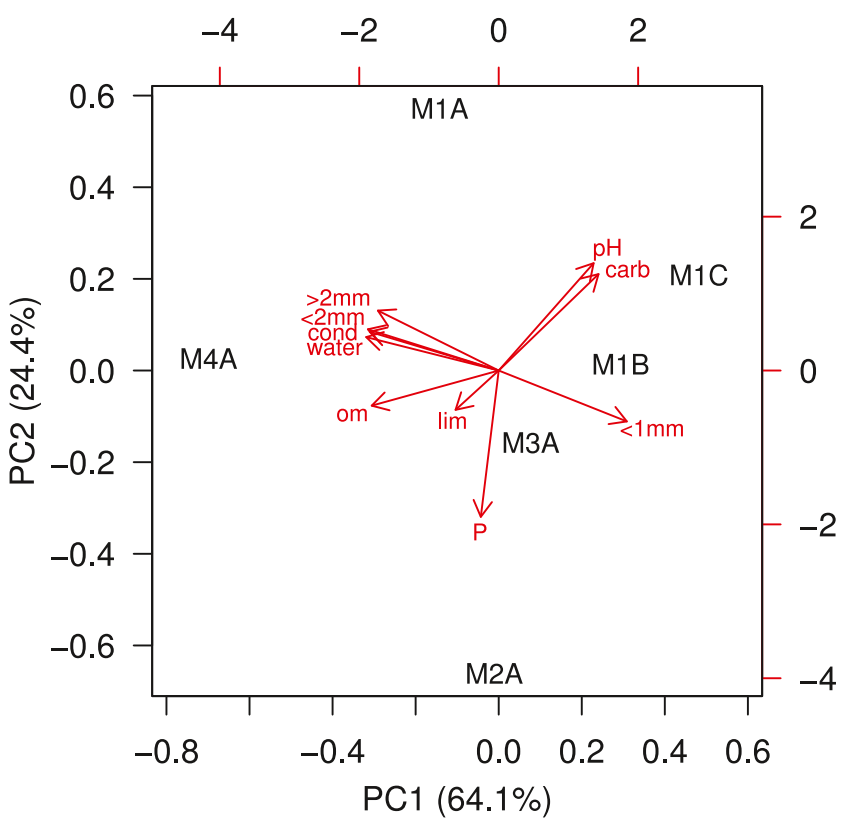

Figure 1 Principal component analysis of soil physicochemical variables scored, showing relationships among soil sampling points. Points M1-4 indicate the number of dune slack, and letters $A-C$ the soil zone (lower salt marsh, intermediate zone, and higher sand dune, respectively). Arrows indicate relative contribution of each variable to the first two components plotted. cond conductivity, carb carbonate content, lim active limestone content, om organic matter content, water water content, $P$ phosphorus content, $<1 \mathrm{~mm}$ particle size below $1 \mathrm{~mm}$, $<2 \mathrm{~mm}$ particle size between 1 and $2 \mathrm{~mm},>2 \mathrm{~mm}$ particle size above $2 \mathrm{~mm}$

whereas M2A presented the highest phosphorus content. In all cases, soil texture was ca. $100 \%$.

\section{Diversity of Root Endophytic and Soil Fungi}

A total of 4,500 root pieces from 15 plants sampled at M1 (nine I. crithmoides from zones A-C, and six I. viscosa from zones B-C) yielded 3,065 endophyte isolates, whereas 99 isolates representing unique fungal colony morphologies were recovered from their respective rhizospheric soils. All of these isolates were first grouped into 240 morphotypes according to colony morphology, and then, the number of groups was reduced to 90 OTUs after sequencing their ITS rDNA region and assessing sequence similarity, using $97 \%$ similarity as cut-edge. The great majority of these OTUs could be assigned to fungal taxa through comparisons with NCBI Taxonomy data and a phylogenetic analysis (Table S2 and Fig. S1 in the ESM). Eighty seven OTUs (96.7\%) belonged to the phylum Ascomycota, while Basidiomycota was represented by three OTUs (3.3\%). OTUs were ascribed to 17 fungal orders, with the Pleosporales being the most represented (28.9 \% of all OTUs), followed by Hypocreales $(21.1 \%)$ and Eurotiales $(15.6 \%)$, while 8 (8.9\%) OTUs could not be assigned to any fungal order. Out of the 90 OTUs, 53 (58.9 \%) were exclusively isolated from roots,
$15(16.7 \%)$ were only recovered from soil, and 22 (24.4\%) were found in both roots and soil (Fig. S1 in the ESM).

Endophyte assemblages from roots of IcA showed a reduced richness, diversity, and evenness as compared to other samples, while occurrence of endophytes was similar (Table 1). This pattern was not followed by fungal communities in rhizospheric soil. Both incidence and abundancebased richness estimators (Bootstrap and Chao) indicated that fungal communities were, in most cases, undersampled, though differences between observed and estimated richness were relatively low (Table 1).

Considering overall root colonization, two OTUs within the Ascomycota were particularly common as endophytes: OTU01 (16.8\% of root pieces colonized) and OTU07 $(13.9 \%)$. While OTU07 could be assigned to the species Fusarium oxysporum by rDNA similarity with GenBank database entries, OTU01 presented a low similarity $(90$ $95 \%$ ) with entries corresponding to Lophiostoma sp. and uncultured or unidentified fungi, and therefore could only be identified as a member of the order Pleosporales. Other relatively frequent OTUs were OTU16, OTU03, OTU05, and OTU23, with isolation frequencies between $4.4 \%$ and $5.6 \%$, while the remaining OTUs were rarely isolated (0.02-1.4\% colonization; Fig. 2, Table S3 in the ESM). Regarding soil fungi, again few OTUs could be considered frequent throughout the survey $\left(>1 \times 10 \mathrm{CFUs}^{-1}\right.$ soil), being only OTU03 coincident with a dominant endophyte (Fig. 2, Table $\mathrm{S} 3$ in the ESM).

\section{Structure and Relationships of Fungal Communities}

Rank-abundance curves calculated from combined data sets per sample revealed typical species dominance profiles within communities (Fig. 2). This dominance was strongest in the endophyte community of IcA, where the Pleosporales OTU01 accounted for $88 \%$ of the species abundance. Occurrence of this fungus dramatically dropped or disappeared in other root samples, though still representing a $13.2 \%$ of all IcB species, and was never recovered from soil. Interestingly, IcA rhizospheric soil communities were also dominated by a Pleosporales fungus, OTU80, which was practically absent in other samples. Dominance of other endophytic communities by different OTUs never accounted for more than $50 \%$ of the species abundance within each sample. Both I. viscosa root samples presented Fusarium oxysporum OTU07 as the dominant species.

Comparisons among fungal communities were performed through calculation of similarity indices and distance-based ordination techniques. Cluster analysis of distances based on incidence data (presence/absence) of both endophytic and soil fungi significantly discriminated (PERMANOVA, $\mathrm{df}=1, P<0.001$ ) both communities (Fig. 3a). Root and soil fungal communities were also 
Table 1 Abundances, richness, and diversity indices of Inula spp. endophytic and associated rhizospheric soil fungal communities by sampling sites

\begin{tabular}{|c|c|c|c|c|c|c|c|c|}
\hline & \multirow[b]{2}{*}{ Sample } & \multirow[b]{2}{*}{ Abundance $^{a}$} & \multirow[b]{2}{*}{$S^{\mathrm{b}}$} & \multicolumn{2}{|c|}{ Richness estimators } & \multicolumn{3}{|c|}{ Diversity indices } \\
\hline & & & & Boot $(\mathrm{SE})^{\mathrm{c}}$ & Chao $(\mathrm{SE})^{\mathrm{d}}$ & $H^{\mathrm{e}}$ & $\alpha^{\mathrm{f}}$ & $J^{\mathrm{g}}$ \\
\hline \multirow[t]{6}{*}{ Endophytes } & IcA & 79 & 13 & $15.8(1.9)$ & $15(5.3)$ & 0.6 & 2.2 & 0.23 \\
\hline & IcB & 81.6 & 35 & $42.1(6.4)$ & $50(24.2)$ & 2.64 & 8 & 0.74 \\
\hline & $\mathrm{IcC}$ & 42.7 & 30 & $36.1(5.2)$ & $35.1(5.9)$ & 2.09 & 7.5 & 0.62 \\
\hline & IvB & 73 & 34 & $40.3(6.6)$ & $35.7(3.0)$ & 2.06 & 7.5 & 0.58 \\
\hline & $\mathrm{IvC}$ & 64.2 & 25 & $30.5(5.1)$ & $28.3(7.6)$ & 2.08 & 5.2 & 0.65 \\
\hline & Overall & 68 & 75 & $91.5(6.9)$ & $85(7.6)$ & 2.71 & 13.9 & 0.63 \\
\hline \multirow[t]{6}{*}{ Soil fungi } & IcA & $1.4 \times 10^{5}$ & 14 & $16.5(2.6)$ & $20(0)$ & 1.71 & 1.1 & 0.65 \\
\hline & IcB & $2.2 \times 10^{5}$ & 19 & $23(3.7)$ & $20.5(7.2)$ & 1.87 & 1.4 & 0.63 \\
\hline & $\mathrm{IcC}$ & $4.6 \times 10^{5}$ & 10 & $11.9(1.8)$ & $10(0)$ & 1.23 & 0.7 & 0.53 \\
\hline & IvB & $2.4 \times 10^{5}$ & 18 & $22.2(2.9)$ & $18(1.3)$ & 2.31 & 1.4 & 0.8 \\
\hline & IvC & $1.6 \times 10^{5}$ & 14 & $16.8(3.2)$ & $15(0)$ & 1.44 & 1.1 & 0.55 \\
\hline & Overall & $2.5 \times 10^{5}$ & 37 & $43.8(3.1)$ & $52(0)$ & 2.44 & 2.6 & 0.68 \\
\hline
\end{tabular}

${ }^{a}$ Abundance is expressed in colonization percentage for endophytes and CFUs $g^{-1}$ of dry soil for soil fungi

${ }^{\mathrm{b}}$ Observed richness

${ }^{\mathrm{c}}$ Bootstrap incidence-based estimate

${ }^{\mathrm{d}}$ Unbiased Chao abundance-based estimate

${ }^{\mathrm{e}}$ Shannon diversity index

${ }^{\mathrm{f}}$ Fisher's $\alpha$ diversity index

${ }^{\mathrm{g}}$ Pielou's evenness index

assessed separately using abundance-based similarity indices and plotting distances by NMDS ordination (Fig. 3b, c). For the endophytes data set, IcA and IcC grouped separately with respect to the remaining samples, as shown by the relative distances among samples in the plot (Fig. 3b), displaying significant differences (PERMANOVA, $\mathrm{df}=4, P<$ $0.001)$. For the rhizospheric soil fungal communities, significant differences were also found when samples were compared (PERMANOVA, $\mathrm{df}=4, P=0.043$ ), accounting for a slight dissimilarity of IcA samples with the rest (Fig. 3c).

\section{Microscopy of Roots}

All samples examined by light microscopy exhibited dark septate fungi (DSF) colonizing the inner root cortex, mainly appearing longitudinally along the root length in the vicinity of the vascular system (Fig. 4a-c). Roots from I. crithmoides in zone A showed an extensive colonization by dark-pigmented hyphae (Fig. 4a), which morphology and abundance varied in upper zones of the sand dune (Fig. 4b). Roots of $I$. viscosa also exhibited diverse root-colonizing DSF morphologies, although these were clearly different from those observed in IcA (Fig. 4c). Only one sample from IvC displayed clear structures from arbuscular mycorrhizae
(AM), such as intra-cellular arbuscules and Glomus-like vesicles (data not shown).

\section{Detection of OTU01}

OTU01 was recovered in culture from roots of all I. crithmoides sampled at zones A of sites M1-4 (Fig. 5a). Conversely, no colonies similar to those of OTU01 developed from leaf or stem pieces, which were found to be colonized by other fungi (Fig. 5a). OTU01 colonization of I. crithmoides roots at M1 (78 \%) and M4 (67.3\%) was significantly higher (ANOVA, df $=3, P=0.009$ ) than at M2 (20.3\%) and M3 (7.7\%). Samples with lower occurrence of OTU01 showed a significantly higher presence of other fungi colonizing roots (ANOVA, $\mathrm{df}=3, P=0.016$ ). Occurrence of OTU01 was positively correlated with soil water content, conductivity, and particle size above $1 \mathrm{~mm}$ (Spearman's rank correlation, $\rho=0.67-0.76, P<0.05$ ), while it was negatively correlated with soil particle size below $1 \mathrm{~mm}$ $(\rho=-0.67, P=0.018)$. All of these were included in the first component of Fig. 1.

OTU01 detection by root culturing in M1 was confirmed by PCR, and it revealed the presence of the fungus in rhizospheric soil, which had not been possible by culture methods (see Table S3 in the ESM). Direct amplification of total DNA extracted from rhizospheric soil and surface- 
Figure 2 Rank-abundance plots showing community structures of endophytic (main plots) and rhizospheric soil (subplots) fungal communities from Inula crithmoides $(\mathbf{a}-\mathbf{c})$ and $I$. viscosa $(\mathbf{d}-\mathbf{e})$, sampled at M1 in zones A (a), B (b and d), and $\mathrm{C}$ ( $\mathbf{c}$ and $\mathbf{e})$. Plots show relative abundances of OTUs sorted by rank order size. Dominant endophytes are indicated next to their respective points (a)

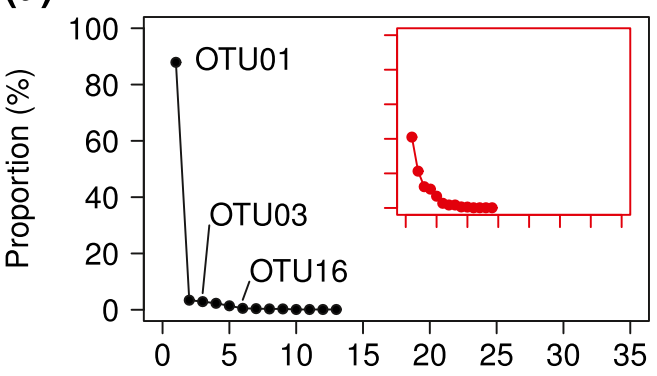

(b)

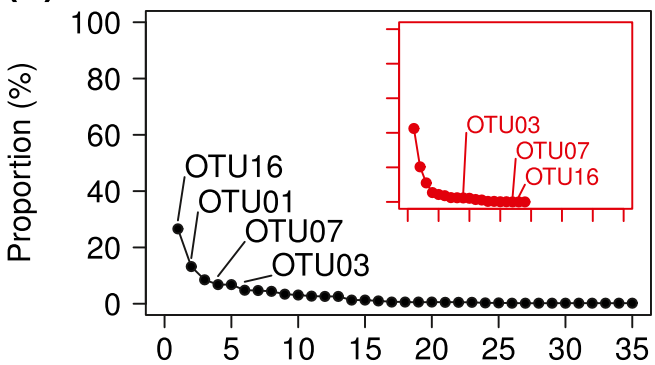

(d)

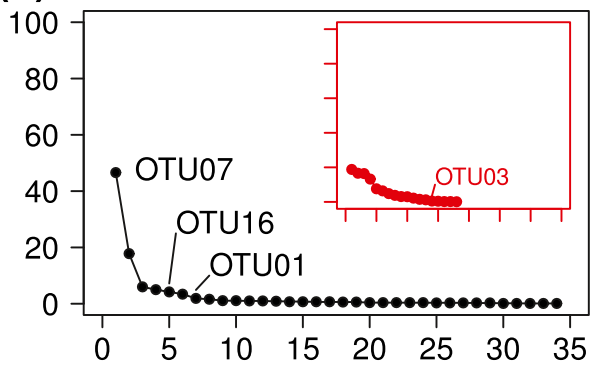

(e)

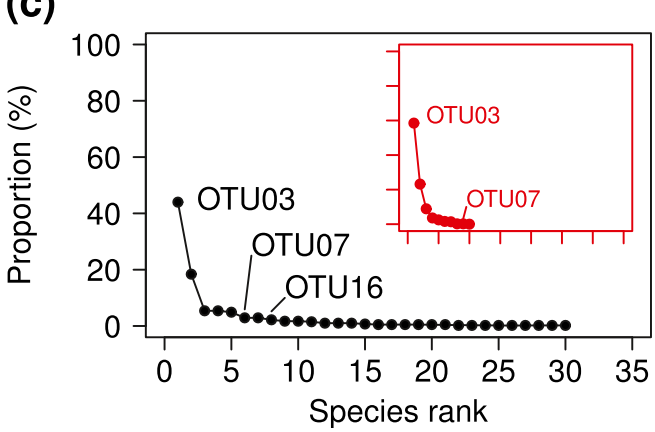

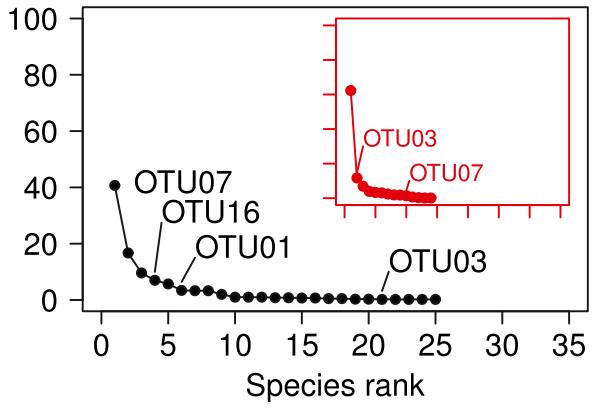

sterilized roots, stems, and leaves with fungus-specific primers ITS1F/4 yielded amplicons of ca. $600 \mathrm{bp}$ in all cases (Fig. 5b). When using OTU01-specific primers ME3F/R, clear amplicons of ca. $230 \mathrm{bp}$ were only observed in soil and root samples. Sequencing of the latter confirmed that these belonged to OTU01 (Fig. S2 in the ESM). DNA amplification from stems and leaves with primers ME3F/R was mainly negative or yielded only weak amplicons (Fig. 5b) which could not be sequenced due to the low quantity of amplified DNA.

\section{Effect of Salt Concentration on Fungal Growth}

Salt concentration (100 mM onwards) severely affected growth rate of OTU01 (Fig. 6a), while it showed little response to low osmotic pressures caused by increasing concentrations of sucrose. This was in contrast with the rest of the fungal endophytes tested (Fig. 6b-d), which were unaffected by neither sodium chloride nor sucrose $(0$ $500 \mathrm{mM}$ ). Growth of rhizospheric soil fungi was also barely inhibited by sodium chloride (data not shown).

\section{Discussion}

The fungal community associated to roots of Inula spp. significantly varied along all factors considered, namely, host plant, edaphic conditions, and substrate of origin (root tissues or rhizospheric soil). Although the sampled area was relatively small (ca. $200 \mathrm{~m}^{2}$ ), its physical and biological heterogeneity favored the occurrence of diverse fungal assemblages adapted to the specific conditions. In the first place, the great differences observed between the root fungal colonizers and those dwelling few centimeters apart in the rhizospheric soil would indicate specific adaptations either by certain fungi to enter and extend within plant tissues or by the host plant to trim among the soilborne-to-endophyte candidates. The latter capacity has been already observed in some plant species [32], and roots of Inula species (including the ones studied here) are known to produce antimicrobial metabolites that may affect their colonization by fungal endophytes (e.g., [33, 34]). Fungi also differ broadly in their ability to invade plant tissues, and probably, the final selection of root colonizers is the result of both plant barriers and fungal capabilities. 
(a)

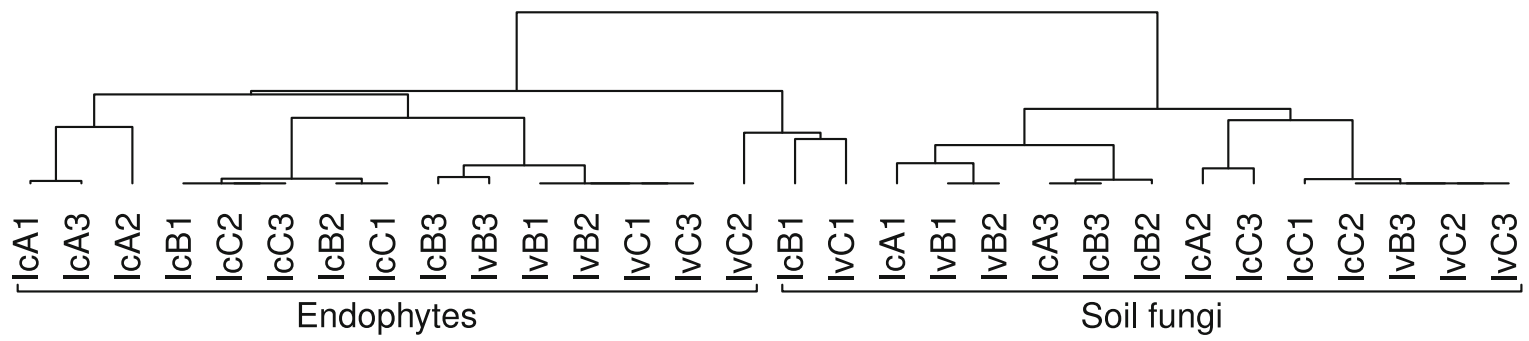

(b)

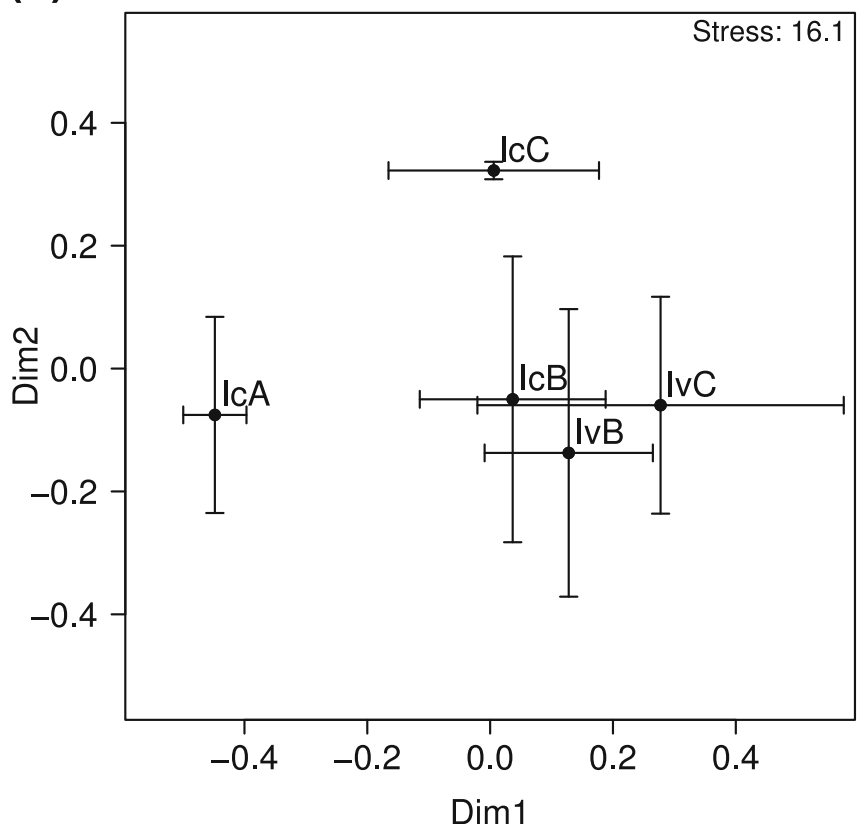

Figure 3 Ordination of fungal communities' data. a Dendrogram constructed by hierarchical clustering of samples from endophytic and rhizospheric soil fungal communities from a combined incidence data set. b Non-metric multidimensional scaling ordination of endophytic fungal communities based on abundance data. c Non-metric

Regarding host plants, endophyte communities of $I$. crithmoides and I. viscosa were only similar in the intermediate zone of the gradient (zone B). This was also the zone with a larger species richness, representing a buffer area with mixed species from both communities, plus a number of highly adaptable other species ("edge effect"; [35]). The halophytic I. crithmoides appeared to harbor a plastic community depending on its position in the dune slack and adapted to the specific site conditions. Conversely, the generalist $I$. viscosa, which can be acting as an invasive plant in the surroundings of the salt marsh due to some degree of habitat degradation [36], presented a single, general association of endophytes capable to withstand diverse physical conditions. Analogous phenomena have been observed in the interaction between plants and root-feeding nematodes: While invasive plant species occupying the habitat of native species are mostly colonized by generalist nematodes, the latter is most commonly colonized by feeding specialists [37]. (c)

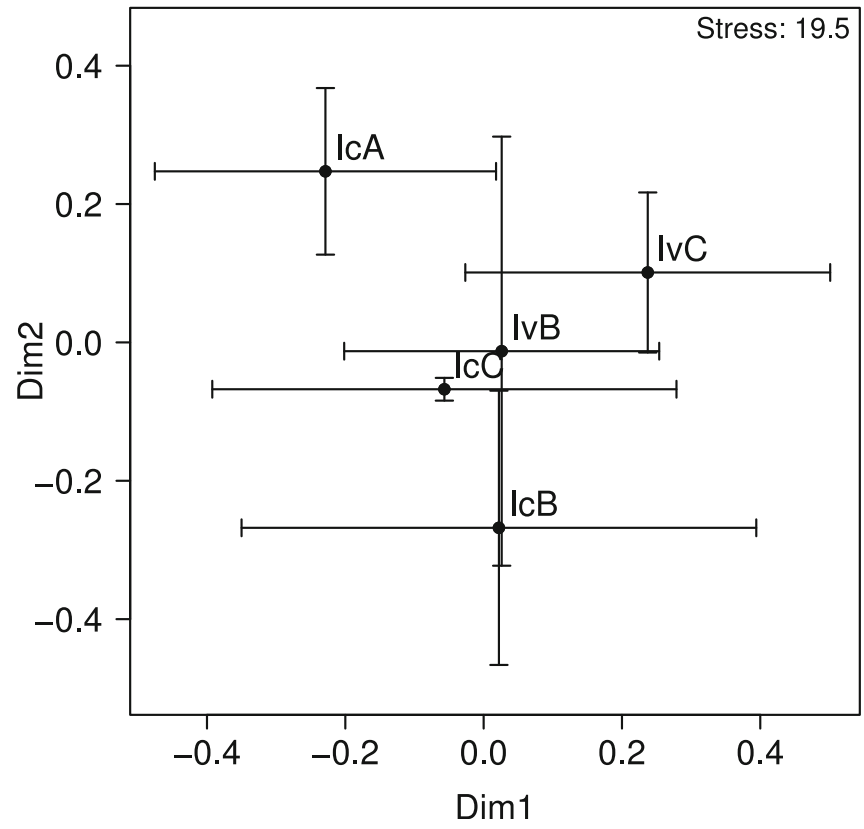

multidimensional scaling ordination of soil fungal communities based on abundance data. Each dot represents the average position of three samples, and bars indicate $95 \%$ confidence intervals in either $x$ or $y$ axes

There was a decrease, from the lower salt marsh upwards, in soil conductivity and water content, influenced by the vicinity to the sea level, and which could be determinants for different types of stressful conditions for plant growth, i.e., salt and drought stress, respectively. The edaphic variations were accompanied by changes on the diversity and composition of endophytic assemblages of I. crithmoides, especially on the lowest part. As previously stated, these effects were diluted in the case of I. viscosa, although its absence in the most salt-affected end of the gradient impeded the evaluation of a stronger selective pressure on its rootassociated fungi. Considering I. crithmoides alone, the first spatial changes observed in the endophytic community consisted of a severe drop of fungal diversity, but not occurrence, in the lower salt marsh. Although similar effects have been previously described, other factors in addition to salinity, such as low oxygen availability, may be involved [38, 39], given the tolerance to high salt concentrations by most of the fungi tested. The edaphic variations were also 


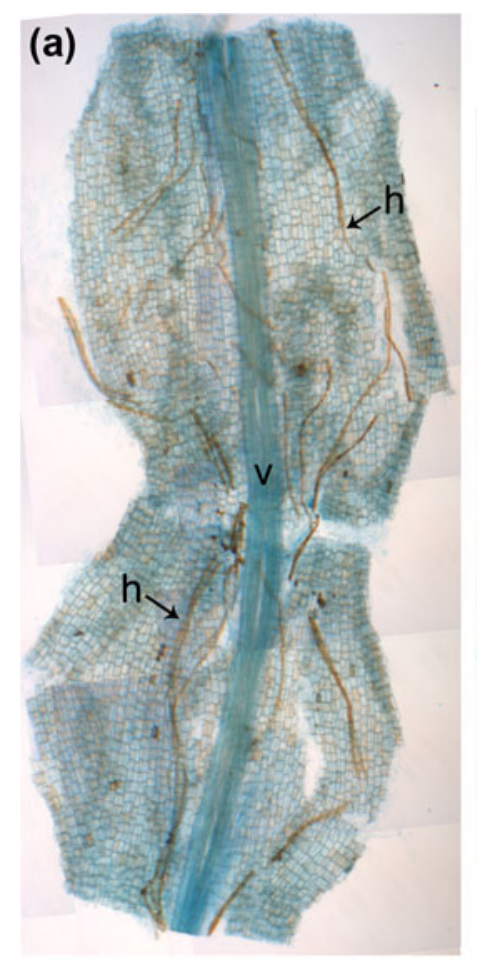

(b)

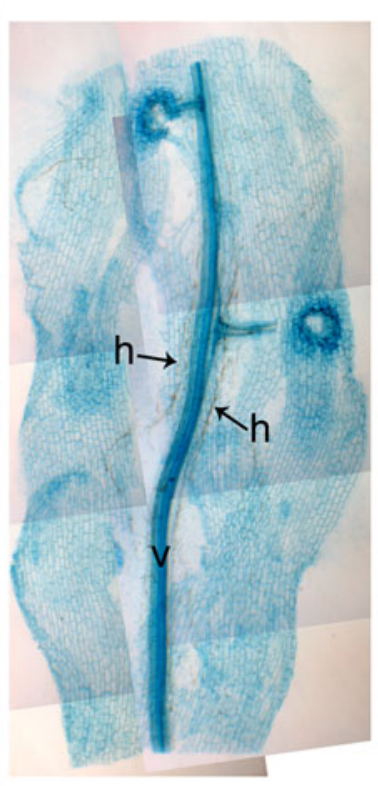

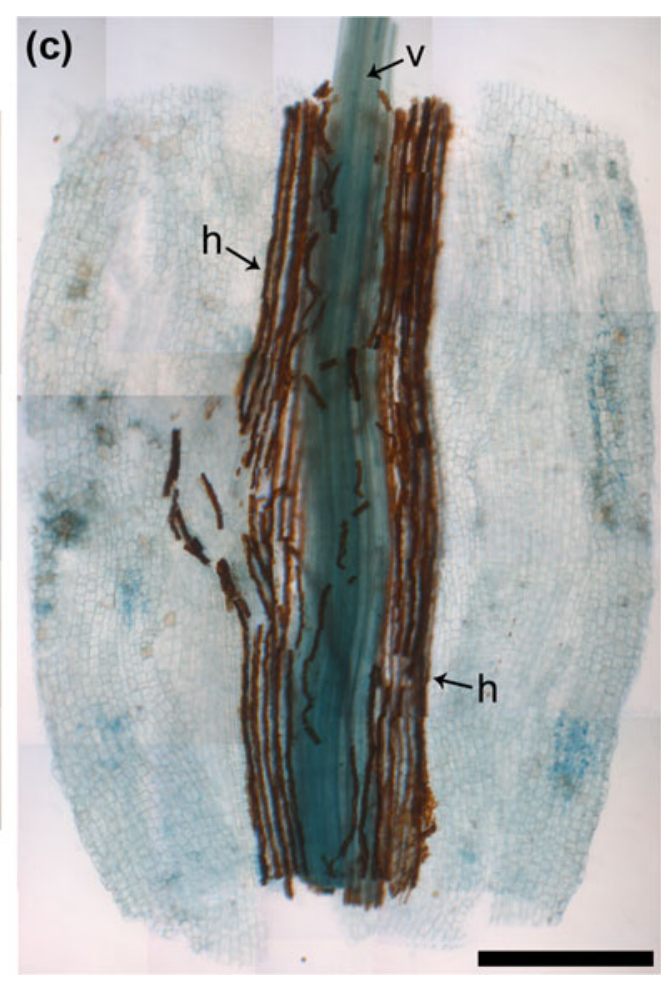

Figure 4 Light microscopy images of root pieces from IcA (a), IcC (b), and IvB (c) extensively colonized by DSF (bar=1 mm). Arrows indicate fungal hyphae associated with root vascular systems. Each image is a composite of several micrographs assembled to cover all the root fragment length. $h$ DSF hyphae, $v$ plant's vascular system (a)

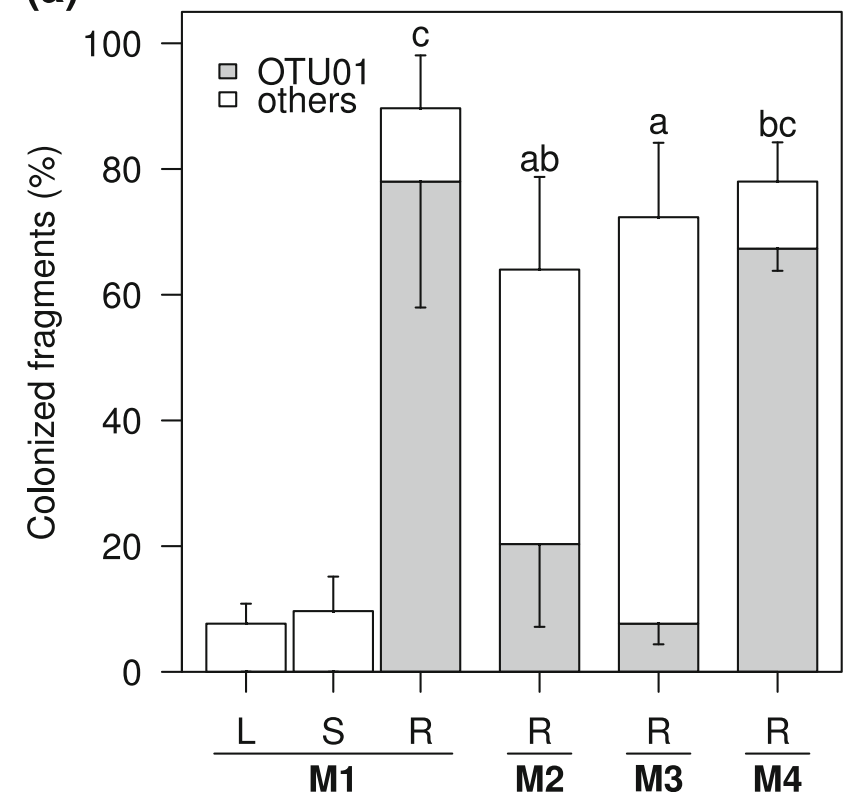

Figure 5 Detection of OTU01 by culturing methods and PCR. a Colonization percentages for OTU01 and other fungi from roots $(R)$, stems $(S)$, and leaves $(L)$ of Inula crithmoides at site M1 and from roots at sites M2-4. Error bars indicate standard errors, and different letters above bars indicate significant differences at $P<0.05$ for OTU01 colonization among root samples. b PCR detection of OTU01 in soil, (b)

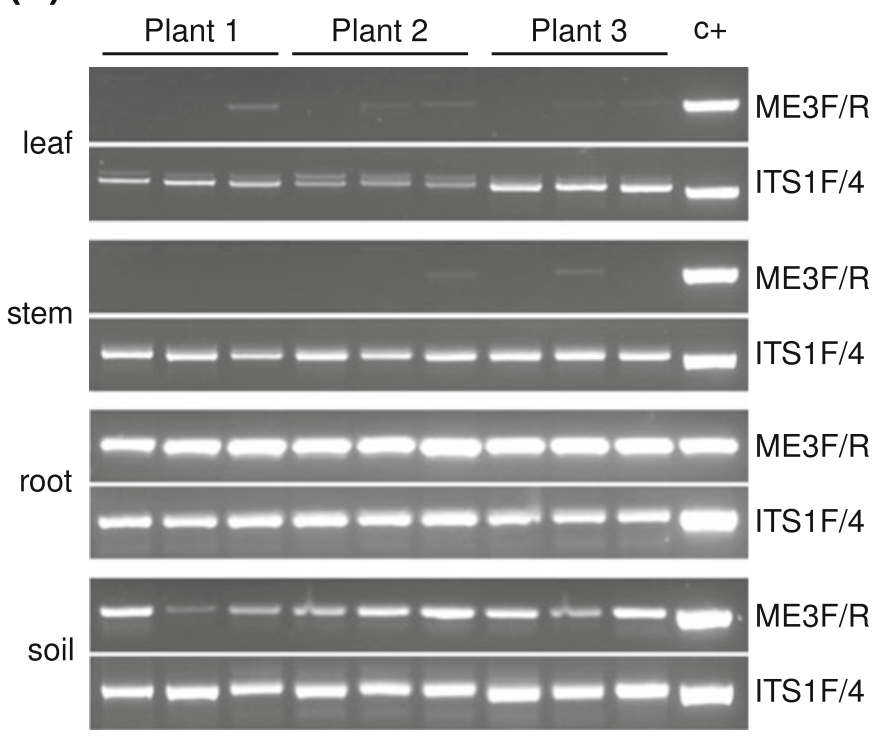

roots, stems, and leaves of three I. crithmoides individuals at M1, using primers ME3F/R. The same samples were also amplified with the universal ITS1F/4 primers as positive amplification controls. A further control $\left(c^{+}\right)$was included in both PCR mixes containing $1 \mathrm{ng}$ of OTU01 genomic DNA. Each different lane consists of a PCR amplification from an independent DNA extraction 
Figure 6 Effects of increasing concentrations of either $\mathrm{NaCl}$ or sucrose on radial growth of main endophytes from roots of Inula crithmoides and $I$. viscosa: OTU01 (a), OTU03 (b), OTU07 (c), and OTU16 (d). Error bars have been omitted for clarity; standard deviations were less than $5 \%$ of the mean value for all cases (a)

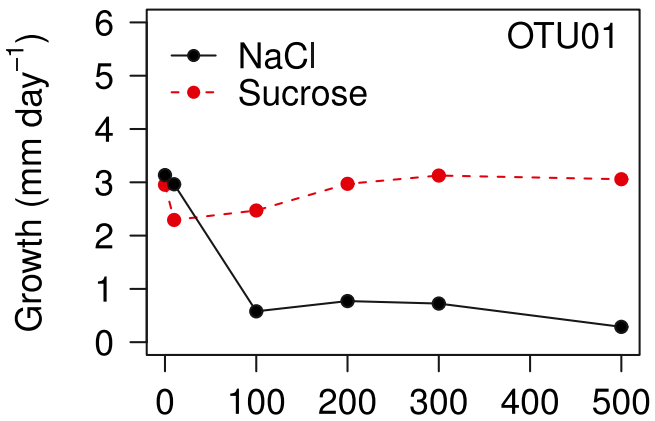

(c)

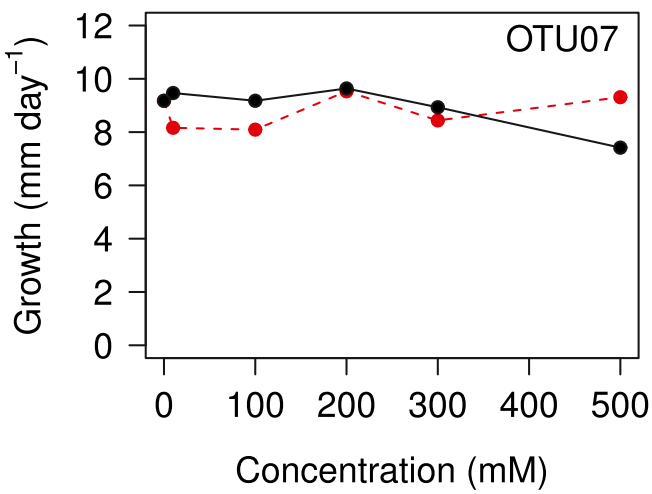

(b)

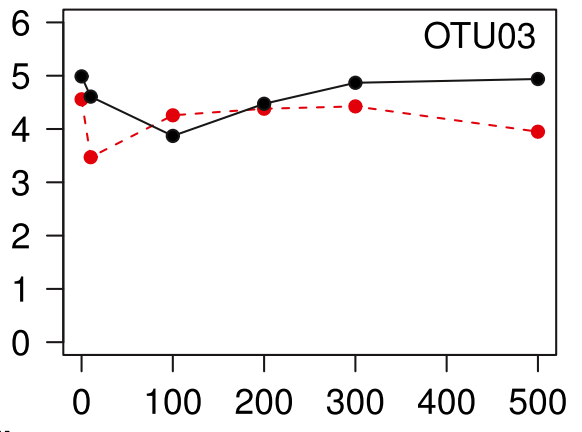

(d)

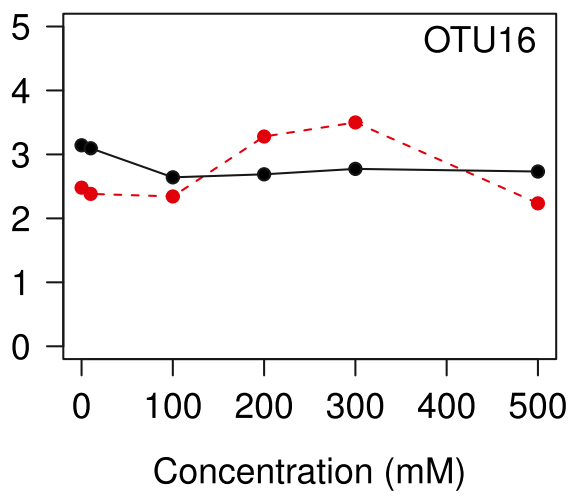

accompanied by a transition in dominance by the fungal order Pleosporales in the salt marsh (mostly represented by OTU01), to the order Hypocreales in the upper dune (Fig. S3 in the ESM). Other examples of this transition, including the same orders and soil conditions, have been previously reported [16]. This suggests general adaptations to these specific situations (e.g., soil salinity) at a high taxonomical level.

An exhaustive characterization of the fungi composing the root endophyte community was carried out by cultivation methods, using a high number of small-sized tissue pieces to maximize the number of recovered isolates [40], plus a further grouping of these by sequencing of the ITS rDNA regions. Although traditional isolation methods have been criticized in favor of cultivation-independent methods [41], the latter presents other drawbacks, yet cultivation is the only mode of physically recovering isolates for experimentation. Comparisons between the herein recovered fungal diversity and that obtained in other works are difficult due to the relative scarcity of similar samplings. In general terms, we cannot conclude that the fungal community reported here is highly divergent from that found in other studies (e.g., [16, 42-44]). Most fungi identified are common endophytes and soil dwellers, albeit, in other cases, BLAST identities matched uncultured fungi, indicating a possible novelty in the strains. As an example, members of genera such as Fusarium, Acremonium (and its close relative Emericellopsis), Alternaria, or Phoma, all known as widespread root endophytes, were frequently isolated. Other fungi included well-known plant and even invertebrate pathogens (e.g., Beauveria bassiana and Arthrobotrys oligospora), which may switch to an endophytic lifestyle in the absence of other hosts.

A great component of the fungal diversity could be somewhat ascribed to dark-septate fungi (DSF), either by mycelial morphology or phylogenetic affiliation [43, 45]. Most of them could be classified within the Pleosporales, as found in previous surveys in Mediterranean [43, 44] or semiarid areas [9, 46-49]. DSF were also abundant within the root tissues, especially along the longitudinal root axis, and appeared tightly associated to the vascular system as previously observed by [9], who postulated that this demand an active participation in a mutualistic relationship with the host.

Among DSF, OTU01 was selected for further studies due to its high dominance of I. crithmoides roots in the lower salt marsh, which represented about $90 \%$ of the isolates. OTU01 is a dark-septate sterile fungus within the Pleosporales, with phylogenetical affinities to the genus Lophiostoma. This genus, together with its relative Massarina [50], is common in marine or estuarine environments, as well as an endophyte of woody plants [51], which may explain its great prevalence in an environment which experiences periodic flooding with saline water. However, Lophiostoma sp. has also been recently found as one of the main DSF endophytes in semiarid grasslands [49], 
which suggest a lesser dependence of aquatic habitats. OTU01 was prevalent in all dune slacks studied, apparently restricted to the plant's radicular systems and extending to the rhizosphere (as revealed by PCR detection of the fungus in soil). The fact that the fungus is unable to reach the aerial tissues discards its vertical transmission and wind dispersion to nearby dune slacks within the host's seeds. Moreover, plant-plant root infection would account for transmission within a salt marsh, but not between dune slacks far apart, which probably occurs by animal transportation of plant debris containing fungal propagules [52], and herbivory and deposition.

Occurrence of OTU01 was positively correlated to high salt content in the soil, which is puzzling taking into account the high sensitivity of the fungus to sodium chloride observed in vitro. Fungal growth appeared strongly inhibited by even low concentrations of salt (much below seawater salinity), probably due to ionic rather than to osmotic stress, given its lack of response to increasing concentrations of sucrose in the culture medium. Such contradictory behavior could be related to an escape by the fungus from adverse environmental conditions (e.g., high salinity) through colonization of plant tissues. In our case, the plant is a halophyte which has structural adaptations to the stress OTU01 cannot cope with. However, other root and soil fungal isolates which were rare or absent in the lower salt marsh were unaffected by sodium chloride, and therefore, we cannot discard the influence of other factors in the definitive fungal distribution in the dune slack. In any case, it is reasonable to propose that OTU01 finds some benefits in colonizing $I$. crithmoides roots in the lower salt marsh, which are translated into an abundant mycelial development. It is also safe to assume that the great fungal loads within the plant root tissues do not come without a cost. In fact, in adaptive terms, a high prevalence of the fungus is not totally incompatible with a slight parasitism [54]. Alternatively, we could hypothesize that OTU01 gives, in turn, some fitness benefits to its host, as occurs in other similar cases [2, 39, 53]. Indeed, DSF are often related to beneficial effects on their hosts' development, including nutrient uptake, growth promotion, or tolerance to environmental stresses, although these are frequently difficult to detect [12]. To this respect, we found growth of I. crithmoides - and seed germination in particular - difficult in the laboratory, and this prevented experimentation with OTU01 and its original host. Using other plants (e.g., barley), we could not find any effect by inoculating OTU01 (unpublished results). Concluding, OTU01, an undescribed Pleosporales, is one of the dominant endophytes in roots of I. crithmoides, a halophyte abundant in the lower part (highly saline) of dune slacks in SE Spain. Although its ecological role is yet unknown, its abundance suggests that it plays an important role in the dynamics and performance of local I. crithmoides populations. In view of the ecological as well as agronomic implications (e.g., adaptation to salinity), the role of OTU01 is worth further investigation.

Acknowledgements This research was funded by the Spanish Ministry of Science and Innovation grants AGL2008-00716/AGR and AGL2011-29297. VF was supported by a grant from the international $\mathrm{PhD}$ program "Frotticoltura Mediterranea," Università di Palermo (Italy). The authors would like to thank Dr. Rusty Rodriguez for his critical reading of the manuscript.

\section{References}

1. Clay K, Holah J (1999) Fungal endophyte symbiosis and plant diversity in successional fields. Science 285(5423):1742-1744

2. Redman RS, Sheehan KB, Stout RG, Rodriguez RJ, Henson JM (2002) Thermotolerance generated by plant/fungal symbiosis. Science 298(5598): 1581

3. Herre EA, Mejía LC, Kyllo DA, Rojas E, Maynard Z, Butler A, Van Bael SA (2007) Ecological implications of anti-pathogen effects of tropical fungal endophytes and mycorrhizae. Ecology 88(3):550-558

4. Rodriguez RJ, Redman RS (2008) More than 400 million years of evolution and some plants still can't make it on their own: plant stress tolerance via fungal symbiosis. J Exp Bot 59(5):1109-1114

5. Arnold AE, Mejía LC, Kyllo D, Rojas EI, Maynard Z, Robbins N, Herre EA (2003) Fungal endophytes limit pathogen damage in a tropical tree. Proc Natl Acad Sci USA 100(26):15649-15654

6. Rodriguez RJ, White JF Jr, Arnold AE, Redman RS (2009) Fungal endophytes: diversity and functional roles. New Phytol 182 (2):314-330

7. Clay K, Schardl C (2002) Evolutionary origins and ecological consequences of endophyte symbiosis with grasses. Am Nat 160 (4):S99-S127

8. Schulz B, Boyle C (2005) The endophytic continuum. Mycol Res 109(6):661-686

9. Porras-Alfaro A, Herrera J, Sinsabaugh RL, Odenbach K, Lowrey T, Natvig DO (2008) Novel root fungal consortium associated with a dominant desert grass. Appl Environ Microbiol 74(9):2805-2813

10. Roda JJ, Díaz G, Torres P (2008) Spatial distribution of arbuscular mycorrhizal fungi in the rhizosphere of the salt marsh plant Inula crithmoides L. along a salinity gradient. Arid Land Res Manag 22 (4):310-319

11. Sieber TN (2002) Fungal root endophytes. In: Waisley Y, Eshel A, Kafkafi U (eds) Plant roots: the hidden half. Marcel Dekker, New York, pp 887-917

12. Mandyam K, Jumpponen A (2005) Seeking the elusive function of the root-colonising dark septate endophytic fungi. Stud Mycol 53 (1):173-189

13. Vandenkoornhuyse P, Baldauf SL, Leyval C, Straczek J, Young JPW (2002) Extensive fungal diversity in plant roots. Science 295 (5562):2051

14. Barrow JR, Aaltonen RE (2001) Evaluation of the internal colonization of Atriplex canescens (Pursh) Nutt roots by dark septate fungi and the influence of host physiological activity. Mycorrhiza 11(4):199-205

15. Curadi M, Graifenberg A, Magnani G, Giustiniani L (2005) Growth and element allocation in tissues of Inula viscosa in sodic-saline conditions: a candidate for programs of desertification control. Arid Land Res Manag 19(3):257-265

16. Maciá-Vicente JG, Jansson H-B, Abdullah SK, Descals E, Salinas J, Lopez-Llorca LV (2008) Fungal root endophytes from natural 
vegetation in Mediterranean environments with special reference to Fusarium spp. FEMS Microbiol Ecol 64(1):90-105

17. O'Donnell K, Cigelnik E, Nirenberg HI (1998) Molecular systematics and phylogeography of the Gibberella fujikuroi species complex. Mycologia 90(3):465-493

18. White TJ, Bruns T, Lee S, Taylor J (1990) Amplification and direct sequencing of fungal ribosomal RNA genes for phylogenetics. In: Innis MA, Gelfand DH, Sninsky JJ, White TJ (eds) PCR protocols: a guide to methods and applications. Academic Press, San Diego, pp 315-322

19. Gardes M, Bruns TD (1993) ITS primers with enhanced specificity for Basidiomycetes: application to the identification of mycorrhizae and rusts. Mol Ecol 2(2):113-118

20. Rice P, Longden I, Bleasby A (2000) EMBOSS: the European molecular biology open software suite. Trends Genet 16(6):276277

21. Katoh K, Toh H (2008) Recent developments in the MAFFT multiple sequence alignment program. Brief Bioinform 9(4):286298

22. Schloss PD, Westcott SL, Ryabin T, Hall JR, Hartmann M, Hollister EB, Lesniewski RA, Oakley BB, Parks DH, Robinson CJ, Sahl JW, Stres B, Thallinger GG, Van Horn DJ, Weber CF (2009) Introducing mothur: open-source, platform-independent, community-supported software for describing and comparing microbial communities. Appl Environ Microbiol 75(23):7537-7541

23. Arnold AE, Henk DA, Eells RL, Lutzoni F, Vilgalys R (2007) Diversity and phylogenetic affinities of foliar fungal endophytes in loblolly pine inferred by culturing and environmental PCR. Mycologia 99(2):185-206

24. Altschul SF, Gish W, Miller W, Myers EW, Lipman DJ (1990) Basic local alignment search tool. J Mol Biol 215(3):403-410

25. Nilsson RH, Bok G, Ryberg M, Kristiansson E, Hallenberg N (2009) A software pipeline for processing and identification of fungal ITS sequences. Source Code Biol Med 4(1). doi:10.1186/ 1751-0473-4-1

26. Wang Q, Garrity GM, Tiedje JM, Cole JR (2007) Naïve Bayesian classifier for rapid assignment of rRNA sequences into the new bacterial taxonomy. Appl Environ Microbiol 73(16):5261-5267

27. R Development Core Team (2009) R: a language and environment for statistical computing. R Foundation for Statistical Computing, Vienna

28. Chao A, Chazdon RL, Colwell RK, Shen TJ (2006) Abundancebased similarity indices and their estimation when there are unseen species in samples. Biometrics 62(2):361-371

29. Anderson MJ (2001) Permutation tests for univariate or multivariate analysis of variance and regression. Can J Fish Aquat Sci 58 (3):626-639

30. Griffiths RI, Whiteley AS, O'Donnell AG, Bailey MJ (2000) Rapid method for coextraction of DNA and RNA from natural environments for analysis of ribosomal DNA-and rRNA-based microbial community composition. Appl Environ Microbiol 66(12):54885491

31. Maciá-Vicente JG, Rosso LC, Ciancio A, Jansson H-B, LopezLlorca LV (2009) Colonisation of barley roots by endophytic Fusarium equiseti and Pochonia chlamydosporia: effects on plant growth and disease. Ann Appl Biol 155(3):391-401

32. Edel V, Steinberg C, Gautheron N, Alabouvette C (1997) Populations of nonpathogenic Fusarium oxysporum associated with roots of four plant species compared to soilborne populations. Phytopathology 87(7):693-697

33. Cohen Y, Wang W, Ben-Daniel BH, Ben-Daniel Y (2006) Extracts of Inula viscosa control downy mildew of grapes caused by Plasmopora viticola. Phytopathology 96(4):417-424

34. Zhao J, Li Y, Liu Q, Gao K (2010) Antimicrobial activities of some thymol derivatives from the roots of Inula hupehensis. Food Chem 120(2):512-516
35. Donovan TM, Jones PW, Annand EM, Thompson FR (1997) Variation in local-scale edge effects: mechanisms and landscape context. Ecology 78(7):2064-2075

36. Wacquant JP, Picard JB (1992) Nutritional differentiation among populations of the Mediterranean shrub Dittrichia viscosa (Asteraceae) in siliceous and calcareous habitats. Oecologia 92(1):14-22

37. van der Putten WH, Klironomos JN, Wardle DA (2007) Microbial ecology of biological invasions. ISME J 1(1):28-37

38. Caravaca F, Alguacil MM, Torre P, Roldán A (2005) Microbial activities and arbuscular mycorrhizal fungi colonization in the rhizosphere of the salt marsh plant Inula crithmoides L. along a spatial salinity gradient. Wetlands 25(2):350-355

39. Mohamed DJ, Martiny JBH (2011) Patterns of fungal diversity and composition along a salinity gradient. ISME J 5(3):379-388

40. Gamboa MA, Laureano S, Bayman P (2003) Measuring diversity of endophytic fungi in leaf fragments: does size matter? Mycopathologia 156(1):41-45

41. Götz M, Nirenberg H, Krause S, Wolters H, Draeger S, Buchner A, Lottmann J, Berg G, Smalla K (2006) Fungal endophytes in potato roots studied by traditional isolation and cultivation-independent DNA-based methods. FEMS Microbiol Ecol 58(1):404-414

42. El-Morsy E-SM (2000) Fungi isolated from the endorhizosphere of halophytic plants from the Red Sea Coast of Egypt. Fungal Divers 5:43-54

43. Girlanda M, Ghignone S, Luppi AM (2002) Diversity of sterile root-associated fungi of two Mediterranean plants. New Phytol 155(3):481-498

44. Girlanda M, Perotti S, Luppi AM (2006) Molecular diversity and ecological roles of mycorrhiza-associated sterile fungal endophytes in the Mediterranean ecosystems. In: Schulz B, Boyle C, Sieber T (eds) Microbial root endophytes. Springer-Verlag, Berlin, pp 207226

45. Jumpponen A, Trappe JM (1998) Dark septate endophytes: a review of facultative biotrophic root-colonizing fungi. New Phytol 140(2):295-310

46. Green LE, Porras-Alfaro A, Sinsabaugh RL (2008) Translocation of nitrogen and carbon integrates biotic crust and grass production in destert grasslands. J Ecol 96(5):1076-1085

47. Porras-Alfaro A, Herrera J, Natvig DO, Lipinski K, Sinsabaugh RL (2010) Diversity and distribution of soil fungal communities in a semiarid grassland. Mycologia 103(1):10-21

48. Herrera J, Khidir HH, Eudy DM, Porras-Alfaro A, Natvig DO, Sinsabaugh RL (2010) Shifting fungal endophyte communities colonize Bouteloua gracilis: effect of host tissue and geographical distribution. Mycologia 102(5):1012-1026

49. Khidir HH, Eudy DM, Porras-Alfaro A, Herrera J, Natvig DO, Sinsabaugh RL (2010) A general suite of fungal endophytes dominate the roots of two dominant grasses in a semiarid grassland. J Arid Environ 74(1):35-42

50. Zhang Y, Wang HK, Fournier J, Crous PW, Jeewon R, Pointing SB, Hyde KD (2009) Towards a phylogenetic clarification of Lophiostoma/Massarina and morphologically similar genera in the Pleosporales. Fungal Divers 38:225-251

51. Hyde KD, Wong WSW, Aptroot A (2002) Marine and estuarine species of Lophiostoma and Massarina. In: Hyde KD (ed) Fungi in marine environments. Fungal Divers Research Series, Hong Kong, pp 93-109

52. Currah RS, Tsuneda A, Murakami S (1993) Morphology and ecology of Phialocephala fortinii in roots of Rhododendron brachycarpum. Can J Bot 71(12):1639-1644

53. Rodriguez RJ, Henson J, Van Volkenburgh E, Hoy M, Wright L, Beckwith F, Kim Y-O, Redman RS (2008) Stress tolerance in plants via habitat-adapted symbiosis. ISME J 2(4):404-416

54. Saikkonen A, Ion D, Gyllenberg M (2002) The persistence of vertically transmitted fungi in grass metapopulations. Proc R Soc Lond B 269(1498):1397-1403 